\title{
Cristina Cárdenas Castillo (2015), Viajeros y educación en México Primera mitad del siglo XIX, Universidad de Guadalajara, \\ Guadalajara
}

\section{Adelina Arredondo}

Universidad Autónoma del Estado de Morelos, Cuernavaca adelinaarredondo@yahoo.com

Este libro es el resultado de una investigación rigurosa, y a través de una redacción fluida y amena incita a la lectura. La forma de narrar este texto mantiene al lector en suspenso, con curiosidad y emoción; asimismo, la secuencia en que se presentan los hallazgos y la unión de los cabos sueltos, al final, se asemeja a como lo haría un detective de una novela policiaca. Otra característica importante de esta obra es la manera en la que se articulan las historias de los personajes, la facilidad para hacer que el lector se introduzca en las aventuras de los viajeros y que se deje llevar por su intuición para atreverse a llenar con sus conjeturas los huecos que la información disponible no aporta.

Este libro de Cristina Cárdenas se disfruta porque atrapa al lector, es decir, una vez iniciada la lectura, se quiere seguir conociendo más sobre los personajes, sus escenarios y sus obras. La autora narra cómo los viajeros de ultramar, concretamente franceses, abandonaron su lugar de origen para emprender una incierta aventura en América, concretamente en México. Aunque es preciso aclarar que no eran viajeros ocasionales sino protagonistas de la historia de la educación, es decir, migrantes que vinieron a México con la idea de establecerse y ejercer la docencia no sólo como una manera de ganarse la vida sino con propósitos humanistas, emancipadores, ilustrados, progresistas o empresariales.

En el preámbulo, la autora introduce al lector al contexto histórico y geográfico de la época, en particular, al mundo de la educación en México y en Francia, a través de este apartado, de los pies de página y de la bibliografía se constata que este libro se realiza a partir de una gran cantidad de fuentes primarias dispersas en el viejo y el nuevo continente, 
en archivos conocidos e ignorados, en diversos países, ciudades e instituciones, en correspondencias personales, periódicos, revistas, opúsculos, discursos, informes y multitud de documentos burocráticos.

La autora argumenta que esta investigación le tomó diez años, por lo que señala que este trabajo es fragmentario, pues aún hay mucho por estudiar y descubrir, no obstante, destaca en este texto la honestidad intelectual, la seriedad de la búsqueda y la rigurosidad de su exposición; este libro se pondera en estos tiempos de auge repentino de publicaciones malogradas y sin fundamentos, de miopía historiográfica que ignora los contextos socioeconómicos, políticos y culturales, de plagios, de desprecio, olvido y pereza para ubicar la propia investigación en un estado del conocimiento amplio, de desconocimiento del trabajo de otros y las influencias mutuas. Cristina, por su parte, da créditos a sus colegas, reconocidos y no tanto, a sus asistentes y estudiantes, así como a las instituciones.

La obra está integrada por tres capítulos, el primero, "Alrededor de la enseñanza lancasteriana", trata de la enseñanza primaria, en la cual el método lancasteriano era la novedad pedagógica que los franceses declaraban conocer. Explica cómo el sistema se difundió ampliamente en el mundo durante las primeras décadas del siglo XIX, asimismo, refiere que los objetivos y la metodología coincidieron con las necesidades de legitimarse políticamente, de construir sistemas de instrucción pública y de formar masivamente a sus maestros de los recién creados Estados latinoamericanos. En cierta forma, la autora comparte las críticas que los educadores, estadistas de la segunda mitad del siglo XIX e historiadores educativos contemporáneos hacen al método lancasteriano y a sus protagonistas, que consiste en dotar de una formación acelerada a niños y futuros maestros, de instruirlos más que educarlos, de organizar la escuela marcialmente más que considerar los intereses infantiles.

Sin embargo, sería mejor referir los antecedentes de la escuela lancasteriana y el nuevo contexto al que se integra, para verla en su propio presente y no desde la posterioridad, pues de no ser así, se ignoran las condiciones sociales en que se establecieron y desarrollaron sus objetivos, no sólo expresos sino latentes, que eran precisamente instruir, sin pretender educar y ni siquiera formar. Para la mayoría, una educación integral no era posible ni hacía falta para ese momento específico de la historia donde se construían las bases de una organización de la producción y del trabajo diferentes.

Aunque otros historiadores del tema en México no lo planteen, ni tampoco la autora que revisamos ahora, el sistema lancasteriano tuvo la enorme fortaleza de aportar las Ilaves del conocimiento a amplios sectores de la población, las herramientas básicas para aprender; desde luego no era lo único, pero sí lo era desde los ojos de los maestros que abandonaron su país después de una revolución truncada y que atravesaron el Atlántico para entregar esas llaves a otros habitantes del planeta que, en condiciones políticas distintas, podrían cambiar el mundo. 
Ese es el imaginario que subyace en los maestros como Germain Nicolas Prissette, originario de Villepreux, quien desembarcó en México en 1822 para morir trágicamente cuatro años después en el mismo puerto de desembarque, al ser desterrado. Según fuentes de la autora fue uno de los fundadores de la Compañía Lancasteriana en México y contribuyó a impulsar las primeras escuelas lancasterianas, cuyo objetivo principal, según él mismo, era "poner al alcance de todas las clases sociales de ciudadanos las luces y los conocimientos". Practicó un periodismo crítico que permitió difundir sus ideas más allá de las aulas y las tertulias. Esta trayectoria la explica la autora, recopilando y contrastando una gran variedad de fuentes.

Pierre Lissaute fue otro personaje similar, impulsor de la escuela lancasteriana de Guadalajara, cuya trayectoria se corta en el capítulo primero para continuar en el tercero, porque también enseñó en el nivel superior. Como Prisette, Lissaute participó intensamente en un periodismo crítico, por lo que fue perseguido por sus ideas libertarias y utópicas. Murió también trágicamente en 1832, defendiendo con las armas sus ideales políticos. No digo más porque esa historia personal es la que está más explicada en el libro de Cristina Cárdenas, gracias a que Lissaute dejó muchos escritos y a que la autora los recopiló con paciencia y orden y los ubicó en el mundo de las ideas y las prácticas educativas de la época.

No obstante, poco se ha ahondado sobre su vida personal de este personaje, especialmente emotiva, los huecos con respecto a Lissaute han sido llenados con conjeturas, lo cierto es que surgen algunos cuestionamientos ¿por qué tanta insistencia de Pierre, quien había obtenido ya su ciudadanía en Estados Unidos y vivía en Nuevo Orleans, para regresar una y otra vez a Guadalajara, cuando era arrestado y expulsado, y sin embargo se internaba de nuevo "de manera furtiva"? ¿Por qué tanto celo por regresar cuando no había una relación orgánica clara con un partido o con un grupo político, pero si un compromiso con sus ideales libertarios que igual podían desplegarse en otros lados? Pues, me permito conjeturar, que había una tapatía en su horizonte, y finalmente, dejó de ser una conjetura cuando se casó en 1829, en Guadalajara.

Otros maestros franceses presentados por la autora como Edouard Turreau de Liniéres fueron menos "revoltosos", éste, según fuentes originales, figuró como fundador de la Compañía Lancasteriana y no Prisette, como se dice en este libro. Luego trabajó en lo que la autora señala como "la primera" escuela lancasteriana en México, "El Sol” (1822), aunque hay evidencias de que antes habían existido otras escuelas lancasterianas y, por tanto no era la primera. Posteriormente, fue contratado por el cabildo de Guadalajara para dirigir la Escuela Normal Lancasteriana, mediante la negociación que permitió rebajar el sueldo inicialmente ofrecido de 3000 pesos anuales, que contrastaba con los 300 anuales que solían recibir los preceptores más humildes. 
El caso de otro maestro resulta polémico, y se trata en el artículo "Las esperanzas traicionadas: El fiasco de Bernard Guignoux". Este viajero francés declaró haber sido "jefe de un instituto considerable en Burdeos y París" y licenciado en letras por la "Universidad de Francia"; sin embargo, ni Cristina ni yo encontramos algún rastro de ello.

Lo cierto es que este personaje logró reformar la escuela normal lancasteriana de Chihuahua con 300 estudiantes, a los que encaminó a los estudios secundarios y consiguió capacitar a futuros maestros que más adelante exhibían el certificado extendido por él para optar por puestos de maestros. A Guignoux le ofrecieron, como a Torreau, un sueldo de 3000 anuales que tampoco le pudieron pagar. Un poco por esa razón y otro poco por el impulso recibido desde las élites locales para establecer una escuela privada muy ambiciosa, Guignoux renunció a la escuela pública dejando a sus ayudantes a su cargo, y aunque ellos no tuvieron la capacidad ni conocimientos que tenía su antecesor, la escuela no se cerró ni se regresó al método tradicional como señalan las fuentes de Cristina.

Mal que bien, la institución continuó con el método lancasteriano, pasando por diferentes maestros y después bajo la dirección del maestro José María Marí desde 1846 hasta 1885. Después de la rigidez con que el maestro francés trabajó con el método lancasteriano, él mismo declaró aplicar posteriormente otros métodos más suaves. Hay que hacer notar que él está trabajando con dos sectores sociales diferentes, la escuela pública lancasteriana, para las masas, y las escuelas privadas en Chihuahua y en la Ciudad de México, para las élites. El hombre fue aprendiendo en su propio camino y modificando y adaptando sus sistemas pedagógicos.

Poco se menciona sobre viajeras francesas que ejercieron la docencia, esto se debe a que no las había. La educación de las niñas, quienes de todas formas no serían consideradas como ciudadanas, no era tan importante. Sin embargo, Cristina Cárdenas encontró vestigios de dos mujeres francesas en Guadalajara que ofrecieron sus servicios como maestras, Benita Cadeau y Angélica Torreau, presumiblemente esposa del maestro ya citado. La primera deseaba abrir una escuela para parteras y ambas deseaban abrir escuelas primarias para las niñas, pero por las razones descritas por la autora, recibieron sendas negativas por parte del cabildo tapatío, y las niñas y las jóvenes se quedaron sin esa formación escolar.

El segundo capítulo, "Enseñanza y saberes útiles", aborda una temática poco trabajada en el medio historiográfico, la enseñanza ligada al mundo del trabajo, a la industria, y el docente enlazado al mundo empresarial.

En este apartado, la autora explica cómo las matemáticas, la física experimental, las lenguas vivas, la química, la mineralogía, la botánica, la farmacia y el dibujo se fueron perfilando por encima de las tradicionales de latinidad y filosofía, aunque no explica que muchas de esas materias estaban ya contenidas en las llamadas cátedras de filosofía, y otras, en las 
mayores. Refiere en su narrativa la Academia de Cadetes fundada en 1822, el Colegio de Minería, las escuelas navales y el Colegio Militar, así como las escuelas de artes y oficios.

Cuatro franceses son revisados por Cristina Cárdenas en este capítulo. No hay datos sobre el arribo a México de Stéphan Guénot, al parecer había sido tesorero del ejército francés y en 1826 daba clases de francés en la Ciudad de México intentando establecer una escuela lancasteriana. Para 1828, inspirado por el socialismo utópico de Fourier, compró un predio en Veracruz y años más tarde organizó un asentamiento con 80 colonos franceses que ascendió a 600 miembros; fundó también una compañía de colonización francomexicana en Dijon. Para entonces ya se habían realizado cuatro expediciones colonizadoras en Veracruz. Pero Guénot acabó dejando todo eso en manos de su hermano para emprender otros proyectos como una compañía de fomento de la industria de la seda en Michoacán y otro para establecer escuelas industriales y sociedades mutuales para auxiliar a viudas y huérfanos. La autora explica cómo se desarrrolló esta historia, hasta la muerte de este personaje, en 1867.

Por su parte, Edouard Turreau de Linières, ya mencionado en el primer capítulo por su participación en la Compañía Lancasteriana, propuso en 1835 un nuevo proyecto educativo que articulaba las escuelas para niños y niñas con el trabajo industrial y talleres productivos en las cárceles. Nuevamente las cuestiones políticas truncaron un proyecto ya aprobado, y Turreau se trasladó a Chihuahua para concluir sus días en 1871 en la Ciudad de México como recaudador de rentas.

Un establecimiento innovador a nivel mundial fue propuesto por Luis Napoleón Jaubert, originario de Barcelonette, quien al parecer llegó a México en 1838 y cuatro años después dirigía, junto con Marc Teissier, un instituto literario en la Ciudad de México. Para 1845 comenzó a organizar el Cimnasio mexicano con la ayuda de los miembros del Ateneo mexicano. El establecimiento tenía como fin formar agricultores, comerciantes, artistas y fabricantes y aun público abierto. Su programa estaba integrado por cinco bloques: lenguas, ciencias, religión, artes y gimnasia, todos complejos, baste decir que el de gimnasia estaba compuesto de ocho materias diversas, de asistencia libre. La autora remarca que esta escuela debe ser considerada precursora de la enseñanza técnica.

Finalmente, se incluye en este capítulo a Camilo Bross, quien rompe la lógica de los viajeros, pues había nacido en el Estado de México de padre francés. Desde muy joven publicó un periódico en el que se criticaba la educación clerical y los sistemas de estudio vigentes. En 1838 se dedicaba al comercio, a la educación y al periodismo en el campo de las ciencias y las artes, en la Ciudad de México. Dio clases en el Colegio de San Juan de Letrán, el Colegio Militar y la Escuela Militar. También publicó una gramática hispano-francesa. En la siguiente década fue funcionario de gobierno y se ocupó de la minería, para finalmente dedicarse a la topografía y la construcción, hasta su muerte en 1888. 
El tercer capítulo, "Enseñanza superior", trata de la enseñanza superior, ocupándose de organizaciones, planes de estudio y materias desde las lenguas modernas necesarias en todas las carreras hasta las cátedras innovadoras de medicina.

Este apartado inicia con una reflexión sobre el papel de las "sociedades de ideas" en el impulso a instituciones liberales de educación superior, entre ellos, los masones, que hicieron posible el abandono de modelos tradicionales. Es así como se crearon las condiciones que dieron cobijo a Pierre Lissaute, de quien ya se habló arriba, pero que se le menciona aquí por haber sido catedrático del Instituto de Jalisco. Por su trayectoria política, sus concepciones pedagógicas, inspiradas en Pestalozzi, su intervención en la educación superior y su proyecto social, Lissaute es analizado ampliamente en este capítulo. No obstante, su efímero paso por la historia de la educación, el francés dejó su huella al menos en el gran interés que la autora le profesa, y no le falta razón.

Una mujer aparece en el capítulo. Si bien Benita Cadeau había sido ya objeto de estudio en el primer capítulo, aquí reaparece para contrastar la falta de atención a sus proyectos de escuela para parteras y campañas de vacunación en México con la acogida que tuvieron en Perú. ¿Por qué la retoma aquí Cristina Cárdenas? ¿Sólo para recalcar cómo Guadalajara perdió una notable emprendedora, galardonada en París y bien recibida y aprovechada en Lima? ¿Sólo para llenar el hueco de la falta de mujeres en la educación superior? No es necesario. Las mujeres no tuvieron ningún espacio, como estudiantes, ni como profesoras, ni como nacionales, ni siquiera extranjeras, simplemente fueron ignoradas en el ámbito de la historia de la educación superior durante el periodo que trabaja la autora, es decir, la primera mitad del siglo XIX. Ella misma lo dice, fue hasta 1861 que se abrió la primera institución de educación "técnica" para parteras en Guadalajara. En todo caso, su lugar, como lo que no fue, pudo haber estado en el segundo capítulo y no en éste.

En seguida hay referencia a dos franceses de efímero paso, Guillaume Faget y Claude Gen, ambos profesores del Instituto de Ciencias del estado de Jalisco en 1827. Al cerrarse el Instituto en 1835 con el régimen centralista, se dedicaron a actividades comerciales. El último de los viajeros estudiado por la autora no es precisamente un francés sino un belga, Pierre Vander Linden. Su impresionante currículum y su experiencia en el campo de la medicina militar le permitieron romper tradiciones e impulsar transformaciones fundamentales en la formación médica, como la unificación de la medicina y la cirugía, que habían sido campos separados.

Este formador de médicos le permite a la autora recorrer los estudios superiores en Guadalajara desde la Real Universidad de Guadalajara hasta el Instituto de Ciencias, que lejos de ser su sustituto, constituyó un establecimiento alternativo. Por cierto que este médico, al igual que otros protagonistas de esta historia, participó también en la política y en la guerra, en este caso contra la invasión estadounidense. 
La autora concluye con una reflexión sobre la "interculturalidad intelectual", que se suscita a partir de los libros que llegan de Europa y se complementa con los viajeros europeos que arriban a América y los que van a estudiar a París. Los que venían de Europa pertenecían a una élite letrada y considera que sus experiencias fueron decepcionantes tanto en el campo de la escuela lancasteriana como en el periodismo. Señala que los que participaron en la educación superior "tuvieron que" combinar esta ocupación con el comercio o la industria.

Será acaso que esto era común entre los catedráticos, pues sólo una minoría podía dedicarse exclusivamente a la enseñanza y la organización. Lo cierto es que la mayoría de ellos, franceses o no, eran a la vez políticos, profesionistas liberales, comerciantes o industriales. Por otra parte, después de hacer una reflexión sobre el concepto de "élite" y "élites", la autora concluye que estos franceses de clase media se integraron a las élites mexicanas. Las propias evidencias que ella presenta no muestran que eso haya sido posible, pues una cosa es que hayan sido acogidos en los espacios sociales de élite y otra que llegaran a compartir con ellos el poder de decisión política, económica o social.

Estos viajeros vinieron de diferentes provincias francesas, no había una corriente migratoria específica, unos tenían medios de subsistencia y capitales y otros no. Como bien señala Cristina, no hay suficientes vestigios para conocer las razones por las cuales abandonaron su país. "Aventura, utopía y huida constituyen razones plausibles", considerando que la restauración de la monarquía en Francia los volvía allá "sujetos perniciosos". Sin embargo, en México tomaron distintos partidos, desde iturbidistas y liberales burgueses hasta libertarios y socialistas utópicos. Sabemos qué hacían aquí pero no sabemos con certeza qué les pasó allá, por qué dejaron su tierra. Razones políticas sin duda, pero también motivos personales que no se limitan a la sed de aventura o la ambición de conocer y ampliar sus horizontes, o quizá cuestiones de amores y desamores, de triunfos y fracasos, de alegrías y sinsabores.

La conclusión general de Cristina Cárdenas es que "los franceses tuvieron un rol primordial en la introducción de la enseñanza mutua y en general en la introducción de los estudios superiores de disciplinas científicas como las matemáticas, la física newtoniana, la economía política, el derecho nacional, la estadística, la botánica, la química y la mineralogía”. En lo personal yo no estaría tan segura de utilizar el concepto "primordial". Hay elementos que nos permiten observar que había en las élites criollas tanto una aspiración de modernizar la educación secundaria y superior precisamente para formar los cuadros de una nación independiente, como de masificar la instrucción primaria para construir una ciudadanía inexistente y las bases de una economía de mercado. Por eso, los pocos migrantes franceses que llegaron en la primera mitad del siglo tuvieron la recepción mostrada en este libro, porque encontraron ya el andamiaje para insertarse.

La ilustración española y criolla, la participación de los diputados novohispanos en las Cortes de Cádiz, el Reglamento General de Estudios (del cual el proyecto educativo de 
Condorcet es un antecedente), la introducción de las escuelas lancasterianas en España, Canadá y Estados Unidos, los viajes del mismo Lancaster y su familia, los viajeros novohispanos y mexicanos a Londres, Nueva York, París o Berlín, las experiencias e iniciativas de preceptores y de empresarios emprendedores en algunas localidades, el activismo político de las organizaciones civiles, como las de los "amigos del país" y las logias masónicas, la circulación de libros y revistas extranjeras, junto con la migración de maestros franceses, las condiciones subjetivas formadas por los educadores de la Colonia, fueron parte del ensamble de causas que permitieron el inicio de la constitución de un sistema complejo de educación nacional.

El nuevo libro de Cristina Cárdenas tiene muchos méritos, pues cubre el periodo menos estudiado por la historiografía de la educación, un segmento ocupacional poco atendido por los investigadores de los migrantes extranjeros, pone énfasis en el potencial de estos personajes como agentes del intercambio cultural y político entre Europa y América Latina y muestra cómo las concepciones educativas liberales se enriquecieron con estos desplazamientos precisamente en la época de su estudio.

Asimismo, permite ampliar y profundizar el conocimiento del siglo XIX y de los procesos de globalización de las ideas y las prácticas educativas. Por su acercamiento historiográfico, por la complejidad explicativa, por su narrativa amena es un libro de lectura imprescindible para los investigadores en el campo, y muy interesante para un amplio círculo de lectores. 